\title{
Association of the types of alcoholic beverages and blood lipids in a local population in Jharkhand, India
}

\author{
Sunil Kumar Verma ${ }^{1}$, Janmejaya Rout ${ }^{2}$, Shrutidhara Biswas ${ }^{3}$, Umakanta Tripathy ${ }^{2 *}$ \\ ${ }^{1}$ Department of Biochemistry, Patliputra medical college, Dhanbad, Jharkhand, 826005, India \\ ${ }^{2}$ Department of Applied Physics, Indian Institute of Technology (Indian School of Mines), \\ Dhanbad, Jharkhand, 826004, India. \\ ${ }^{3}$ Department of Biotechnology, Indian Institute of Technology, Guwahati, Assam, 781039, \\ India. \\ *Corresponding author: utripathy@ iitism.ac.in
}

"This manuscript has been withdrawn by the authors due to confusion over posting
policies. The authors request that you do not cite this work as reference for the
research described. Please contact the corresponding author if you have any
questions." 